\title{
Households as infrastructure junctions in urban sustainability transitions: The case of hot water metering
}

Harald Rohracher and Helena Köhler

The self-archived postprint version of this journal article is available at Linköping University Institutional Repository (DiVA):

http://urn.kb.se/resolve?urn=urn:nbn:se:liu:diva-159233

N.B.: When citing this work, cite the original publication.

Rohracher, H., Köhler, H., (2019), Households as infrastructure junctions in urban sustainability transitions: The case of hot water metering, Urban Studies, 56(11), 2372-2386.

https://doi.org/10.1177/0042098018815618

Original publication available at:

https://doi.org/10.1177/0042098018815618

Copyright: SAGE Publications (UK and US)

http://www.uk.sagepub.com/home.nav 


\title{
Households as infrastructure junctions in urban sustainability transitions - the case of hot water metering
}

\author{
Harald Rohracher (corresponding author) \\ Department of Thematic Studies - Division of Technology and Social Change \\ Linköping University, 58183 Linköping, Sweden \\ Tel.: +46 700896002 \\ E-Mail: harald.rohracher@liu.se
}

Helena Köhler

Department of Thematic Studies - Division of Environmental Change

Linköping University, 58183 Linköping, Sweden

Tel.: +46 13-28 2282

E-Mail: helena.kohler@liu.se

\begin{abstract}
The integration of infrastructure domains and resource flows such as electricity, heat, water and waste increasingly gains currency in strategies to achieve more resource-efficient, smart and resilient cities. While widely discussed concepts of a nexus of resource systems, such as energy-water-food, aim at a more optimised and integrative management of resource flows, this article investigates how infrastructure integration is accomplished through the establishment of new interfaces and junctions between formerly separated systems. In particular, it focuses on households as an arena where different urban infrastructures intersect and different kinds of sometimes contradicting demands are imposed to co-manage these infrastructures, such as the case of own electricity generation from photovoltaics along with the charging of electric cars and the management of household energy consumption. The installation of meters and the constant monitoring of resource use and consumption feedback to household members is regarded as a crucial element in such a transition towards more sustainable urban infrastructures. Empirically the article studies the introduction of hot tap water meters in urban households in Sweden and the resistance and reactions of these households to such a metering regime. Our study shows how meters as new junctions between energy suppliers and users but also between separate infrastructures of electricity, hot tap water and room heating become contested political terrains which are linked to broader socio-political questions of urban change. In contrast to system management perspectives, such an 'inside-out' approach rather lends itself to more contextsensitive and navigational governance approaches of infrastructure integration.
\end{abstract}




\section{Introduction}

The transformation and integration of urban infrastructures for energy, water, mobility or waste has become a core tenet of strategies for sustainable development, just as policies towards more resource-efficient, resilient or smart cities are receiving high priority (Frantzeskaki et al., 2017; Bulkeley et al., 2011). Such approaches are often characterised by a "paradigm of integration" of so far separated infrastructure sectors and resource flows in order to achieve more overall efficiency and policy coherence (Wichelns, 2017; Cairns and Krzywoszynska, 2016). This new discursive focus appears to be inspired by both technological developments and more holistic approaches to the management of socioecological and socio-technical systems.

Three perspectives on infrastructure integration stand out in this respect: (1) The electricity system is perceived to shift from a system of centralised, large-scale production to a much more distributed system based on renewable energy which requires more flexibility in matching supply and demand (Ruth and Kroposki, 2014; Wu et al., 2016). Part of this energy system flexibility is supposed to be achieved through a tighter coupling with other infrastructure sectors such as waste (flexible energy generation through waste incineration or biogas generation - see Moss, this issue), transport (electric vehicles, biofuels) or agriculture (biogas production, co-generation of heat and electricity). (2) A second 'discourse of integration' is driven by the increased use of information and communication technologies (ICT) in energy and other infrastructure systems and the potential for more distributed and horizontal forms of coordination and control through e.g. 'smart grids' (Hojčková et al., 2018). (3) A further perspective is the integration and joint management of resource flows through a nexus of energy-water-agriculture and other systems (Endo et al., 2017). The broader launch of this term is often traced back to the Bonn 2011 Nexus Conference, organised by the German Federal Government (ibid.: 20; Kurian, 2017). An author collective of reknown researchers on global environmental change names "urbanization and resource nexus" as one of the three overarching global change problems in the anthropocene (Brondizio et al., 2016) and calls for new forms of analysis going beyond sectorial resource systems of food and energy production, water security and biodiversity resilience (p. 324).

These discourses of systemic integration of infrastructure sectors and their related resource flows share a techno-managerial approach of system management. Also nexus concepts are dominated by engineering approaches - the 'pumps and turbine approach' as Scott et al., 2011 , call it referring to the energy-water nexus - and characterize nexus mainly in resource efficiency terms, e.g. cubic meters of water needed to generate a kilowatt hour of electrical power (ibid., p. 6622). Similar to the idea of smart grids as a new form of integration (Schick and Winthereik, 2013), the term nexus is only vaguely defined and rather functions as a buzzword (Cairns and Krzywoszynska, 2016), which evokes certain imaginaries (such as the 'integrative imaginary', ibid., p. 166) with a strong normative resonance. Having analysed the application of the nexus concept in UK and international research and policy contexts, Cairns and Krzywoszynska (2016) observe a "growing dominance of certain uses of the nexus over others, with integrative and managerialist approaches gaining ground" (p. 167). Also more social science oriented researchers who in general contribute to opening up these technocentric approaches put forward a "more comprehensive understanding of the links between energy and water, to identify where better-integrated policy and management strategies and solutions are needed, and to understand where barriers exist to achieve that integration." (Hussey and Pittock, 2012) These researchers emphasise the need to "include institutions and decision making in the water-energy nexus" (Scott et al., 2011: 6629), i.e. focus more on the social processes of resource management than purely on the outcome of optimized 
systems. Such 'integrative imaginaries' of nexus thinking and system management are also dominant at the urban scale: a 'resource-efficient city' is seen to require an integrated management of different resource flows, such as the above mentioned energy-water nexus or the use of waste for energy generation; a 'smart city' integrates information and communication technologies across infrastructure domains; and the 'resilient city' addresses the effects of increasingly interdependent and tightly inter-connected infrastructures (Monstadt and Coutard, 2018, this issue).

However, while new connections between infrastructures undoubtedly are gaining ground, e.g. by producing bioenergy from waste or making electric cars part of household energy management, these new interfaces do not necessarily reflect an integrated resource management perspective as envisioned in the nexus approach. In this paper we will complement the paradigm of an integrated management of infrastructure and resource systems as it is articulated in the nexus debate, with a process perspective highlighting new infrastructure connections (or junctions) in the making. Such a perspective foregrounds the openness and contestedness of these processes and their embeddedness in socio-political contexts. Instead of asking for ways of implementing integrated infrastructure and resource systems in a managerial and apolitical way, we rather look for the micro-politics of emerging new social practices and socio-technical configurations around urban infrastructure interfaces and the tensions and conflicts this creates. While the term 'nexus' highlights the general interconnectedness of resource flows, the term 'junctions' rather draws our attention to new interlinkages created between infrastructures or resource systems. In consequence, such an approach also opens up for other kinds of policies and strategies aiming at urban sustainability transitions and a more sustainable resource use.

Households are a particular place where many of the above-mentioned interfaces (e.g. between electricity supply and consumption, between microgeneration, electricity storage and electric vehicles) are situated and infrastructures become integrated in the practices of everyday life. We ask: How are new interfaces of infrastructures and resource flows created and (re)configured at the level of urban households and to which extent are they becoming political terrains where not only questions of sustainable resource use but also other sociopolitical questions of urban development, such as segregation or a just distribution of infrastructure costs, are fought out? Empirically, we want to study such processes through the case of new metering devices in households. Meters for electricity, water or other resources can constitute an important element of the interlinkage and interdependency of infrastructures, just as they are the sites for coordinating the use of infrastructure services with sometimes contradictory requirements of an efficient and sustainable provision of electricity, heat, electro-mobility and micro-generation. Through the increased use of ICT, 'smart meters' are becoming a much more active element of managing the interrelation between infrastructure service providers and their users, but potentially also between different types of infrastructures (e.g. charging an electric vehicle battery at times of electricity supply from own PV). Our claim is that particular dynamics of change emerge at these interfaces and reconfigure the use of resources, though often in ways different from the intentions of the utilities or housing companies aiming at integrative resource flow management and installing these meters.

New generations of meters thus potentially occupy a key place in concepts of a better integration and management of future infrastructures and resource flows - they are not only supposed to register resource consumption but also to constantly provide feedback to users and intervene in their behaviour. In consequence, such meters give rise to new relations between supply and demand side actors, new distributions of responsibility and the 
establishment of joint regimes of use across different types of infrastructure. They are a "'gateway' technology around which the most significant transactions between utilities and their customers are based" and "changes in the functionality, control and purpose of metering systems has key implications for the social relation between users and suppliers of essential resources" (Marvin et al., 2011:175). Which socio-technical configurations and practices actually emerge around metering devices thus depends not only on management concepts for a better resource use, but as much on the socio-political relations and contexts these meters become part of, the visions and practices of different actor groups linked to these infrastructures, and the controversies and sense-making processes accompanying their introduction.

Our concrete empirical case is the implementation of new metering devices for hot tap water in a Swedish city and its knock-on effects on resource efficiency for not only tap water but also heating and electricity. Our plan is not to follow a straightforward story of achieving increased resource efficiency and service integration through the introduction of new metering strategies and consumption feedback, but to look out for the context-dependence of such changes, the frictions such attempts to manage resources more efficiently may create, and the close inter-linkage of urban and infrastructural change.

\section{Households as arenas of infrastructure transformation}

Conceptually, we draw on different approaches which provide us with an 'inside out' perspective on infrastructure transformation processes. Recent actor-network-theory-inspired approaches - mostly in an urban studies context - such as 'navigational governance' (Jørgensen, 2012), 'transition mediators' (Jensen et al., 2015) or 'urban green assemblages' (Blok, 2013) replace perspectives of a techno-economic management and optimisation of infrastructure change with a perspective organized around different social arenas where problems of change are interpreted and framed differently and where conflicting perspectives come to the fore. A crucial issue for an assessment of transformative dynamics and identification of promising strategies in such a perspective is the identification of junctions and intersections where such tensions and conflicts arise which open up new opportunities for negotiations and change.

Interpreting the opening of the Copenhagen harbour to bathing, Jensen et al. (2015) understand this development not merely as a bounded niche in which new (and potentially more sustainable) socio-technical configurations are tested and stabilized. Such projects, they claim, also mediate between different infrastructure systems, different logics of demand and supply, and between social groups with particular interests. They form intersections at which different visions and perspectives of urban change are confronted with each other, are negotiated and may eventually lead to the emergence of new socio-technical configurations, e.g. through repercussions of harbour bathing on the wastewater infrastructure. The authors introduce the notion of 'junction' for such place specific catalysts or mediators of far-reaching change processes (Jensen et al., 2015).

Potentially, the introduction of new metering devices equally creates such 'junctions' for change processes across infrastructures and mediates wider urban transformations.

Experiments (and new legal provisions) for moving a whole block of apartments or buildings behind a joint meter, for example, open up for increased local self-supply from renewable electricity with yet uncertain impacts on electricity generation and distribution infrastructures. As households also connect different types of infrastructures, changes in one of these networks may mediate or catalyse through households a reconfiguration of other systems as 
well - e.g. changes in the energy efficiency of buildings can mediate changes in the structures of heat supply (making e.g. district heating uncompetitive) and create frictions and controversies between the actors involved (Späth and Rohracher, 2015). Households are places where infrastructures are "inhabited by urban dwellers" and "reinterpreted through use", as Latham and Wood (2015:300) put it. The different ways how citizens interact with infrastructures can be seen as "windows into social worlds" which reflect "larger scale social forms" such as "patterns of social integration and fragmentation, uneven geographical development and collective social imaginaries" (Angelo and Hentschel, 2015:306).

Households provide an arena, where different actor perspectives and expectations come together around such junctions of infrastructures, where processes of sense-making take place and new understandings of sustainability emerge and are negotiated.

Concepts of junctions have been long adopted in other STS and innovation studies literature. Two inspiring examples, which can also be applied to current transformations centring on households, are the work of Ruth Schwartz Cowan on 'consumption junctions' (Schwartz Cowan, 1987) and the historical study by Onno De Wit et al. (2002) on offices as innovation junctions. Schwartz Cowan focuses on "the place and time at which the consumer makes choices between competing technologies, and try to ascertain how the network may have looked when viewed from the inside out (...)." (p. 263) Following the history of US home heating and cooking systems during the past 250 years, she finds that these changes are not so much shaped by new technologies than by e.g. new structures of the industry, contingent events or various features of the socio-technical networks consumers have been embedded in. Onno de Wit et al. (2002) are less interested in choices between competing technologies, but in innovations due to the co-location and combined use of different sets of technologies in offices and the need to find arrangements to coordinate them. Their historic studies reveal different dynamics of change than in large technical systems and various forms of integration through interfaces for the combined use of certain technologies, functional integrations etc. usually in the absence of system builders. Current infrastructure integration in households seems to have many parallels to these historic cases.

In a similar vein, Head et al. (2013) conceptualise households as 'connected households' linking up with wider systems of provision and socio-economic networks and containing their own complex politics and practices (p. 352). Attempts to govern the change of households towards more sustainability intervene in these connections and may create zones of traction and zones of friction, characterising pathways of change where resistance comes to dominate or where successful reconfigurations of the connections between households and systems of provision take place. In a similar way, it should be possible to analyse such zones of friction and traction in the new re-connections of infrastructure systems and households.

So, what do these approaches add to studying the integration of infrastructure systems? While the energy-water-food nexus, as discussed in the introductory chapter, focuses on the management of resource systems in a more integrative and optimised way, the focus on junctions and the creation of new interfaces between infrastructures at places of use highlights a different dynamic of integration and establishment of new connections. What is interesting with new junctions or interfaces at household level, is that this perspective highlights new connections in the making, the unexpected knock-on effects across infrastructures and the new frictions and contestations which may arise by reconfiguring infrastructures in households. The outcome of these processes might significantly deviate from 'optimised system integration' and might become closely linked to various problems of urban development, as our empirical case will show. Meters are an excellent place to study such dynamics because they are closely linked to the management of resource use and the 
more active coupling of resource systems such as electricity, heat and transport (e.g. to avoid peak loads). Moreover, their purpose is to serve as interfaces between households and infrastructure use and as a communication device between suppliers and users of energy or water. The next section will take stock of some of the recent research on the role of meters.

\section{Metering devices as mediators of new infrastructure constellations}

The importance of metering devices, in particular in connection with the recent development of smart meters, for the configuration of energy systems has been pointed out repeatedly in the research literature. Their capacity to shape social relations between users and suppliers is particularly conspicuous in contexts where infrastructure systems are less stabilised and settled, such as in less industrialised countries of the global south. Antina von Schnitzler $(2008 ; 2013)$ has traced the 'travels' of prepayment meters from their early use in late $19^{\text {th }}$ century Britain to their introduction in a South African pre- and post-apartheid context and shows convincingly how meters can become "a political terrain for the negotiation of central ethical and political questions concerning civil virtue and the shape of citizenship" (Von Schnitzler, 2013:689). During the apartheid era, a prepayment meter programme was set up as a reaction against non-payment of utility bills and widespread rent boycotts in the 1980s. Pre-payment meters turned the collective boycott action into an individual decision whether to buy electricity or not and were thus used as a 'depoliticising device' based "on a sociology of counter-insurgency that viewed the user as a political obstacle to be silenced" (von Schnitzler, 2008:912). This role shifted in the post-apartheid era and in an increasingly neoliberal governance context, where such meters rather were conceived as a pedagogical technique to produce 'calculative citizens' who were able to equate their daily energy consumption practices with monetary value. The capacity of electricity meters to become a political terrain where socio-political conflicts are fought out, is also at the centre of a study of the role of electricity meters during the privatisation of the electricity network in Nicaragua (Cupples, 2011) - meters are a core element of the socio-material enactment of the exclusions and social injustices of privatisation in this case, but they were also enrolled in creative ways to resist these changes. A further field where meters, and again in particular smart meters with prepayment functions, take on a central role in the socio-material enactment of socio-political relations is their use in the governance of fuel poor households. A study on the introduction of smart prepayment meters for fuel poor households in Austria (Berger, 2016) revealed how those devices (much as their 'mechanical' predecessors) shifted responsibility for staying connected to the electricity grid from the public utility to the household and how they have inbuilt 'pedagogical components' requiring to repay some of the financial debt to the utility each time a new electricity budget is uploaded to the meter.

Apart from fuel poverty, the impact of (smart) meters is mainly discussed in terms of feedback on energy consumption and the reduction of energy use this allows. Such meters and visualisation tools open up new 'calculative spaces' (Callon and Muniesa, 2005) and can be perceived as 'technologies of responsibilisation' (Soneryd and Uggla, 2015) which intend to shift the responsibility for energy consumption to choices at the individual level. As Darby (2008; 2010) points out, there is however no clear evidence for such energy-saving effects of smart meters. However, instead of looking on feedback on consumption in isolation, one should rather focus on broader 'advanced metering infrastructures' which embed this feedback in different kinds of business models or services offered to electricity customers. Only through whole 'infrastructures of demand reduction' (Darby, 2008), through the creation of 'reflection practices' around the use of smart meters (Pullinger et al., 2014) or through a 'co-management of everyday practices' aiming at the reconfiguration of practice components 
(rules, meanings, material infrastructures etc.) in ways that instigate less resource-intensive processes (Strengers, 2011) can shifts to a more sustainable energy system be achieved. A key point in these analyses is again to perceive metering devices as only one element of a wider socio-material assemblage. The agency of these meters and the changes they make to energy practices is an emergent outcome of these assemblages and their social and political contexts and not of the particular metering design alone. This is also important, if one looks at the interaction of network-bound infrastructures at the level of households. Although systems of energy, water and wastewater provision have undergone similar transformations in the course of liberalisation and privatisation of infrastructures (e.g. differentiation of providers, technologies, services, but also of the role of consumers) and metering again assumes an important role in mediating these new relations of service provision and consumption, the impact of these changes on consumer practices is quite different within the different socio-technical make ups of these sectors (van Vliet, 2012; 2016). It is remarkable, though, how the very same domestic consumers smoothly combine the use of these different network-bound services - where they e.g. have to make active service choices with electricity, while still being treated as 'captive consumers' with waste and wastewater together within their household practices (van Vliet, 2012:274).

What this short journey through literature on meters for energy and other resources already makes clear, is that meters are much more than neutral monitors of resource flows which easily lend themselves to an integrated management of infrastructures and resources. Analysing meters as 'political terrain', identifying 'zones of friction' in infrastructure transformation, or studying the dynamics of junctions between infrastructure systems, can help us to understand the interwovenness of the materiality of particular infrastructure elements with the socio-political discourses, actor strategies and shifts of power relations that emerge around them. We will apply such a perspective in the next section to an empirical case of a newly introduced hot tap water metering regime in Sweden and will subsequently discuss the different types of insights this generates in comparison to a system analysis of connected resource flows.

\section{Metering controversies - introducing heat and hot tap water meters in Swedish homes}

Sweden has been one of the forerunner countries in introducing advanced electricity metering systems (smart meters). The situation is almost the opposite for the metering of space heating and hot tap water consumption. This particularly applies to multi-apartment buildings which in Sweden are almost exclusively supplied with district heating (Magnusson, 2012) - and thus is an element of a particularly urban infrastructure setting. In these apartments, space heating, water and hot tap water costs are usually included in the rent without separate metering. This applies to both dominant ownership forms of multi-apartment buildings: those owned by a housing company and rented to tenants (about $60 \%$ of all apartments, of which $50 \%$ are owned by public housing companies) and co-operatively owned buildings. This situation has come under scrutiny as a consequence of the EU Energy Efficiency Directive (2012/27/EU) requiring Swedish legislation to stipulate individual metering of household energy usage for resource efficiency reasons, if cost effective and technically feasible. Although many housing cooperatives did not show much willingness to install devices for individual metering and debiting (IMD) (Siggelsten and Olander, 2013), the pending legal requirement caused some housing companies to experimentally introduce individual metering in some city districts. 
This has also been the case in the city of Linköping, the fifth largest municipality in Sweden with about 153000 inhabitants, where the municipal public housing company, installed individual meters for hot tap water and apartment temperature loggers in 48 households in autumn 2013. If proven technically feasible, the intention was to eventually extend individual metering to about 12000 of the company's 18500 apartments. In the initial phase, no individual costs were charged for hot tap water, though households were informed that this was eventually the intention. The temperature loggers were not installed for debiting purposes, but to enable remote reading of apartment temperature. This move to individual metering was part of the housing company's efforts to comply with its own environmental goals ( $25 \%$ less bought energy by 2025$)$ and contribute to the city's environmental efforts.

In spring 2014, 13 households with 18 informants participated in a social science study of water routines. They wrote a time-diary for 3 days and were interviewed individually or groupwise, in order to establish their original water use routines and their thoughts of being measured and billed according to their actual hot tap water usage. At this time, the households had not received any individual feedback on hot water usage. Household hot tap water metering data was also collected. A follow-up study was performed in 2016, comprising 11 of the 13 original households. The households were interviewed once more, and household metering data on hot water usage over time was collected. At this moment in time, individual payment according to usage had still not come into effect. The aim of the follow-up was to investigate whether the knowledge alone of having meters installed had changed water use behaviour and how people reasoned about installed meters which were then not used for individual monitoring of consumption. To cover the reasons behind the failed debiting six interviews were conducted with housing company representatives and from the Tenant's Association (for more details see also Köhler, 2018). As we will see below, the practices of hot water usage and metering are connected in various ways to other resources such as electricity.

Some interviewees openly confirm that unmetered hot water often leads to higher consumption levels. As woman $\mathrm{K}$ (with high usage) puts it: "I take water for granted, it is included in the rent and I do not care if one or a hundred litres run away. I can tell the kids to turn off the tap, but it is because I am annoyed by the sound not because I am concerned about the water. If IMD is introduced I will become more aware to avoid high costs, but I do not find it ok since we pay a high rent already today." Also woman E, who takes baths instead of showering says, "I am aware of that baths demand more water so I believe it will be dreary to have to pay for hot water, I believe it would lower the standard of living [...] it was positive to live in a rental apartment that you did not need to pay, think of hot water." Another male (A) user even admits to run warm baths just in order to additionally heat the flat. And indeed, a study of the Swedish Energy Agency finds that hot tap water consumption per person is significantly higher in apartments than in private houses (58 vs $42 \mathrm{l} / \mathrm{d}$ ). ${ }^{1}$

Interestingly, people seem to be able to rather easily switch usage routines depending on the wider contexts of use and 'energy assemblages' they are part of. As the excessive hot water user from above admits: "In the country where I am from you pay for the water you use and it makes you more aware, but here I take it for granted and it is included in the rent." (woman K) Or: "In the summer cabin we have our own well and it has always been like "turn off the water'. There is always a risk that it runs dry. We also have a hot water boiler of 15 litres, which makes us fast in the shower. But you can wash your hair with 15 litres. At the summer cabin you need to be more careful, that you do not need to be in the flat to the same extent."

${ }^{1}$ see http://www.energimyndigheten.se/statistik/bostader-och-lokaler/forbattrad-energistatistik-ibebyggelsen-och-industrin/matningar-av-varm--och-kallvattenforbrukning/; accessed 3 July 2018 
(couple P). Woman $\mathrm{E}$ thought that hot water cost would be added to her rent and she reduced her showers and baths. However, realising debiting would not happen she returned to old routines: "...I thought if I now should pay for water too I have to start saving [...]. Now I laugh up my sleeve when I nestle down in my bathtub" [...]. Others also point out that having lived in a private house, with many to share a limited boiler capacity and payment according to usage, makes you aware of water usage in a different way.

Informants in principle also agree that paying for individual hot tap water usage would increase awareness and have an effect on the level of hot water use and in general could be a reasonable thing to do. Nevertheless, they also have a number of arguments to oppose such a change in the organisation of the hot water and heating system. One issue is mistrust in the intentions of the housing company: "Who gets the money? It will not lead to a lower rent, they (the housing company) will make up other ways of getting that money. It always is about money." (male M) "They will surreptitiously increase the rent, and I will get cheated and I do not like it." (male O). Some informants point to the fact that they already have a contract which includes hot tap water, and that this contract needs to be renegotiated including a lowered basic rent.

IMD on hot tap water shifts not only costs but also responsibility from the housing company to the tenant. A couple of tenant informants are frustrated about the fact that they get this responsibility without the ability to control all hot water using features in the home. A common issue is the quality of hot water. As male A says, "I measured in a bucket and it was 10-12 liters before it felt hot what so ever and it is a drawback since it is a lot of waste per day, it can be like 70-100 liters". Electricity is paid for individually, and even though this is less of an issue due to long historical traditions and that the same 'quality' is provided instantly, male $O$ makes analogous remarks on electricity: "I do not find electricity motivated to pay for individually in rented apartments since the things that need a constant electricity supply I do not possess... it is fridge and freezer and stove, they are the stuff which demands most electricity." It is likely that the housing company's interest to save on energy and water resources decreases if tenants are getting the bill.

The current non-metering of hot tap water and heat for charging purposes also shapes the interfaces and resource use relations of district heating and electricity infrastructures in interesting ways. The housing company connects dishwashers to cold water, meaning that hot water in dishwashers is heated electrically and not through district heating which would be more resource efficient but would leave the costs with the housing company. Similarly, the housing company installs electrical towel-heaters in renovated bathrooms instead of connecting them to the heating system, again a rather in-efficient choice in an apartment already supplied with hot water through district heating. Moreover, space heating is provided to households at temperature levels which are deemed sufficient in relation to parameters like outdoor temperature and in relation to the temperature logger's information. The temperature logger is placed centrally in the apartment and does not always appropriately reflect the temperature in all rooms. Some respondents witness apartments being too cold, forcing them to install electrically heated radiators as a backup or even to take hot baths. The absence of individual metering for tap water and the related question of who pays for which resources thus shapes the nexus between hot tap water, heat and electricity systems in particular, and in this case, resource inefficient ways.

Another tension, which would re-surface through individual metering, regards inequity and solidarity in sharing hot water costs. Currently, each household carries average hot tap water costs per square meter through the rent. This not only means that efficient hot tap water users subsidize inefficient ones, but households with more square meters per person 
subsidize also densely populated households. Indeed, there is some awareness about this situation among household interviewees. As couple M asks: "Should we pay less than the neighbour because they have more kids? How will they do this?" Or male A: "If you get a decreased rent when you decrease your hot water use, it will make people think. On the other hand, you cannot punish someone because there are many people in one flat." Paying for actual usage of hot tap water would thus not only contribute to a more efficient resource use but compared to the current practice also disadvantage households with a higher number of residents per area. These households can primarily be found in residential areas at the fringes of the city, the so-called "million programme areas", erected during the Swedish housing boom of the 1960-1970s and now often economically disadvantaged and with a high share of immigrants. And indeed, the current pilot project is placed in a similar area, though with the intention to eventually expand it to other parts of the city.

The apprehensiveness of the housing company to touch on these socio-economic and potentially conflict-laden issues and differences with the Tenants' Association about the recalculation of rents, if hot tap water costs are paid by households individually, so far has prevented the introduction of such 'payment by usage'. Further steps to introduce individual metering in other areas of the city or use them for individual billing in the apartments of the pilot area have been stopped, even though the use of these meters is regarded as a move towards increased resource efficiency by the housing company, Tenants' Association and as the quotations above give evidence of - by many of the tenants.

\section{Discussion and conclusions}

Despite the rather limited focus of our case study on just one particular infrastructure interface in a Swedish city, our example demonstrates many of the dynamics of infrastructure and resource integration proposed in our introductory and conceptual part. Although restricted to hot tap water measurement, the meters in Linköping established new junctions not only between infrastructure providers and households, but also between different infrastructure systems by linking hot tap water usage with electricity use and space heating. Moreover, these meters were part of a broader 'regime of metering' (along with smart electricity meters and ambitions to also meter space heating) aiming to make individuals more responsible for resource consumption and the environment, establishing regulatory regimes of financial incentives to optimize resource consumption, embedding metering devices in broader ICT infrastructures, and becoming part of a broader transition of infrastructures towards more sustainability and reduction of resource usage. In this sense, our case of hot tap water metering stands in for broader transformations of resource management.

More importantly, however, our empirical case shows how moving from general concepts of optimised and integrated urban infrastructure systems - as reflected in the ambitions of creating a resource nexus and integrated infrastructures - to studying emergent practices and socio-political tensions around new interfaces between infrastructures provides a very different picture. No doubt, particularly urban infrastructures are becoming increasingly interlinked and those new interfaces between supply and demand or across different infrastructure sectors have a significant potential to reduce resource use and greenhouse gas emissions. But there is no general and straightforward way to integrate infrastructure systems and make resource consumption more efficient, as the concept of a resource nexus implicates. How such attempted integration processes actually unfold and which configurations emerge, often happens in rather unexpected ways. 
The introduction of meters for hot tap water in Linköping as part of broader efforts to meter resource consumption across infrastructures (in accordance with the EU energy efficiency directive) has been a failure because it has, among others, underestimated the obduracy of historic traditions of covering space heating and water costs through the rent and thus averaging them out across all customers of the public housing company. The meters installed in the pilot project consequently have never been used to individually charge for hot tap water or to provide other feedback on consumption but have instead become a political terrain where various controversies are being fought out. The controversies have brought up the issue of a fair distribution of hot tap water costs between inefficient and efficient resource users, between the housing company and tenants as a group, but also between different socio-economic groups (related to population density in apartments) with a spatially uneven distribution across the city. Resisting metering for some residents also expressed solidarity with those having larger families or living in economically more deprived parts of the city groups which potentially would have to pay more under the individualised metering regime. Moreover, questions of trust in the public housing company came to the fore - Would they use this opportunity to overcharge customers and increase their profits? - a question likely to be influenced by the context of an increased corporatisation and neo-liberally inspired management of public services. As contested political terrains, new couplings between infrastructure and resource systems thus also become an arena where urban change and visions of urban futures are negotiated.

What the example of hot tap water metering also shows, is how (even failed) attempts to introduce metering can create new linkages and boundaries between infrastructure domains. These new linkages may even run counter integrated resource management efforts: both the housing company by not connecting dishwashers and towel heaters to district heating, and households by installing additional electric heaters, contributed to an even more inefficient resource use across the electricity and heat domain. Instead of optimized technical solutions to make energy, water or food systems more sustainable, we find context-specific sociomaterial assemblages of infrastructure use which create their own dynamics, frictions and outcomes.

What we see is a situatedness and multiplicity of urban infrastructure configurations - in other words, the multiple geographies of nexus raised in the introduction. This is in line with Lawhon et al.'s (2018) recent critique of the normative ideal of universal, uniform infrastructure and their suggestion to replace it with the notion of 'heterogeneous infrastructure configurations' which might "involve many different kinds of technologies, relations, capacities and operations, entailing different risks and power relationships." (p. 720) The integration of resource flows will remain in-effective, as long as institutional restrictions and the influence of historical, spatial and socio-political dimensions are not sufficiently considered. Instead of designing 'grand plans' for integrating and optimizing resource systems which resonate so well with the concept of a nexus of different resource flows, our study rather suggests an 'inside-out approach' of looking for the agencies, practices and dynamics emerging at different junctions - in our case metering devices within and between resource infrastructure systems. Achieving more sustainable urban infrastructures rather requires interventions sensitive to local contexts and socio-political dynamics than system management approaches to create resource nexuses and integrated infrastructure systems.

So, what does this mean for 'nexus policies'? Approaching the resource nexus from the practices and locations where new interfaces are enacted opens up for more differentiated and context-specific urban policies and governance strategies. Jørgensen (2012) suggests a 
concept of 'navigational governance' which does not build on a privileged management position outside the resource system, but which rather accompanies, moderates and intervenes in conflicts and processes of sense-making from within. Taking up our case of hot water metering again, this infrastructure intervention aiming at a more efficient use of warm water has created an arena where concerns about different urban socio-political issues become articulated and where cultural contexts and traditions of resource use are made visible. Enforcing the techno-economically optimal solution apparently failed, resulting in not changing the currently unsustainable use of hot water at all. An alternative would be to work with tenants and find ways to address the broader questions of urban change simultaneously - the disproportional infrastructure and resource costs for economically disadvantaged tenants, the responsibilities of municipal utilities and housing companies for a more efficient resource use, or the fear of finally being 'ripped-off' by profit-driven housing companies. This could in consequence mean that it is maybe not primarily the single household but the housing company which should be addressed in the Swedish context; or that questions of segregation or housing quality have to be addressed simultaneously with questions of resource efficiency.

A nexus between resource systems, particularly important in cities with their high density of infrastructure networks and intensity of resource consumption thus indeed remains a 'troubled concept' as Cairns and Krzywoszynska (2016, p. 169) call it. A concept which rightly points to problems in our current use of natural resources, but which at the same time resists attempts for simple solutions with a managerial and apolitical framing. Questions of infrastructural change and management remain deeply entangled with socio-political question of urban change and urban futures and require situated approaches, acknowledging frictions and tractions at the interfaces of different infrastructures, and navigating the controversies and negotiations between the different parties involved.

\section{References}

Angelo $\mathrm{H}$ and Hentschel C (2015) Interactions with infrastructure as windows into social worlds: A method for critical urban studies: Introduction. City 19: 306-312.

Berger T (2016) Energiearmut in Österreich aus sozio-technischer Perspektive. Klagenfurt: University of Klagenfurt.

Blok A (2013) Urban Green Assemblages: An ANT View On Sustainable City Building Projects. Science \& Technology Studies 26: 5-24.

Brondizio ES, O’Brien K, Bai X, Biermann F, Steffen W, Berkhout F, Cudennec C, Lemos MC, Wolfe A, Palma-Oliveira J and Chen C-TA (2016) Re-conceptualizing the Anthropocene: A call for collaboration. Global Environmental Change 39: 318327.

Bulkeley H, Castán Broto V, Hodson M and Marvin S (2011) Cities and Low Carbon Transitions. London: Routledge.

Cairns R and Krzywoszynska A (2016) Anatomy of a buzzword: The emergence of 'the water-energy-food nexus' in UK natural resource debates. Environmental Science \& Policy 64: 164-170.

Callon M and Muniesa F (2005) Economic Markets as Calculative Collective Devices. Organization Studies 26: 1229-1250.

Cupples J (2011) Shifting Networks of Power in Nicaragua: Relational Materialisms in the Consumption of Privatized Electricity. Annals of the Association of American Geographers 101: 939-948. 
Darby S (2008) Energy feedback in buildings: improving the infrastructure for demand reduction. Building Research \& Information 36: 499-508.

Darby S (2010) Smart metering: what potential for householder engagement? Building Research \& Information 38: 442 - 457.

De Wit O, Van den Ende J, Schot J and Van Oost E (2002) Innovation junctions. Office technologies in the Netherlands, 1880 - 1980. Technology and Culture 43: 50-72.

Endo A, Tsurita I, Burnett K and Orencio PM (2017) A review of the current state of research on the water, energy, and food nexus. Journal of Hydrology: Regional Studies 11: 20-30.

Frantzeskaki N, Castán Broto V, Coenen L and Loorbach D (2017) Urban Sustainability Transitions. London: Routledge.

Head L, Farbotko C, Gibson C, Gill N and Waitt G (2013) Zones of friction, zones of traction: the connected household in climate change and sustainability policy. Australasian Journal of Environmental Management 20: 351-362.

Hojčková K, Sandén B and Ahlborg H (2018) Three electricity futures: Monitoring the emergence of alternative system architectures. Futures 98: 72-89.

Hussey K and Pittock J (2012) The Energy-Water Nexus: Managing the Links between Energy and Water for a Sustainable Future. Ecology and Society 17: 31.

Jensen JS, Lauridsen EH, Fratini CF and Hoffmann B (2015) Harbour bathing and the urban transition of water in Copenhagen: junctions, mediators, and urban navigations. Environment and Planning A 47: 554-570.

Jørgensen U (2012) Mapping and navigating transitions-The multi-level perspective compared with arenas of development. Research Policy 41: 996-1010.

Köhler H (2018) Learning from a failed project - challenges of implementing 'green' technology in a real world setting. Scottish Geographical Journal: 1-14.

Kurian M (2017) The water-energy-food nexus. Trade-offs, thresholds and transdisciplinary approaches to sustainable development. Environmental Science \& Policy 68: 97-106.

Latham A and Wood PRH (2015) Inhabiting infrastructure: exploring the interactional spaces of urban cycling. Environment and Planning A 47: 300-319.

Lawhon M, Nilsson D, Silver J, Ernstson H and Lwasa S (2018) Thinking through heterogeneous infrastructure configurations. Urban Studies 55: 720-732.

Magnusson D (2012) Swedish district heating-A system in stagnation: Current and future trends in the district heating sector. Energy Policy 48: 449-459.

Marvin S, Chappells H and Guy S (2011) Smart Meters as Obligatory Intermediaries: Reconstructing Environmental Action. In: Guy S, Marvin S, Medd W and Moss T (eds) Shaping Urban Infrastructures: Intermediaries and the Governance of SocioTechnical Networks. London: Earthscan, 175-191.

Pullinger M, Lovell H and Webb J (2014) Influencing household energy practices: a critical review of UK smart metering standards and commercial feedback devices. Technology Analysis \& Strategic Management 26: 1144-1162.

Ruth MF and Kroposki B (2014) Energy Systems Integration: An Evolving Energy Paradigm. The Electricity Journal 27: 36-47.

Schick L and Winthereik BR (2013) Innovating Relations - or Why Smart Grid is not too Complex for the Public. Science \& Technology Studies 26: 82-102.

Schwartz Cowan R (1987) The consumption junction. A proposal for research strategies in the sociology of technology. In: Bijker WE, Hughes TP and Pinch T (eds) The Social Construction of Technological Systems. Cambridge, MA: The MIT Press, 261280. 
Scott CA, Pierce SA, Pasqualetti MJ, Jones AL, Montz BE and Hoover JH (2011) Policy and institutional dimensions of the water-energy nexus. Energy Policy 39: 66226630.

Siggelsten S and Olander S (2013) Individual metering and charging of heat and hot water in Swedish housing cooperatives. Energy Policy 61: 874-880.

Soneryd L and Uggla Y (2015) Green governmentality and responsibilization: new forms of governance and responses to 'consumer responsibility'. Environmental Politics 24: 913-931.

Späth P and Rohracher H (2015) Conflicting strategies towards sustainable heating at an urban junction of heat infrastructure and building standards. Energy Policy 78: 273-280.

Strengers Y (2011) Beyond demand management: co-managing energy and water practices with Australian households. Policy Studies 32: 35-58.

van Vliet B (2016) Innovation in Urban Networks: Co-evolving Consumer Roles. In: Hodson M and Marvin S (eds) Retrofitting Cities. London: Routledge, 86-104.

van Vliet BJM (2012) Sustainable Innovation in Network-Bound Systems: Implications for the Consumption of Water, Waste Water and Electricity Services. Journal of Environmental Policy \& Planning 14: 263-278.

von Schnitzler A (2008) Citizenship Prepaid: Water, Calculability, and Techno-Politics in South Africa. Journal of Southern African Studies 34: 899-917.

von Schnitzler A (2013) TRAVELING TECHNOLOGIES: Infrastructure, Ethical Regimes, and the Materiality of Politics in South Africa. Cultural Anthropology 28: 670-693.

Wichelns D (2017) The water-energy-food nexus: Is the increasing attention warranted, from either a research or policy perspective? Environmental Science \& Policy 69: 113-123.

Wu J, Yan J, Jia H, Hatziargyriou N, Djilali N and Sun H (2016) Integrated Energy Systems. Applied Energy 167: 155-157. 